This item was submitted to Loughborough's Research Repository by the author.

Items in Figshare are protected by copyright, with all rights reserved, unless otherwise indicated.

\title{
Low pressure microfilter design aspects and filtration performance
}

PLEASE CITE THE PUBLISHED VERSION

http://dx.doi.org/10.1080/01496390903054561

PUBLISHER

(C) Taylor \& Francis

VERSION

AM (Accepted Manuscript)

LICENCE

CC BY-NC-ND 4.0

REPOSITORY RECORD

Stillwell, Michael T., Wiwit Sumritwatchasai, R.G. Holdich, and S.R. Kosvintsev. 2009. "Low Pressure Microfilter Design Aspects and Filtration Performance". figshare. https://hdl.handle.net/2134/5418. 
This item was submitted to Loughborough's Institutional Repository (https://dspace.lboro.ac.uk/) by the author and is made available under the following Creative Commons Licence conditions.

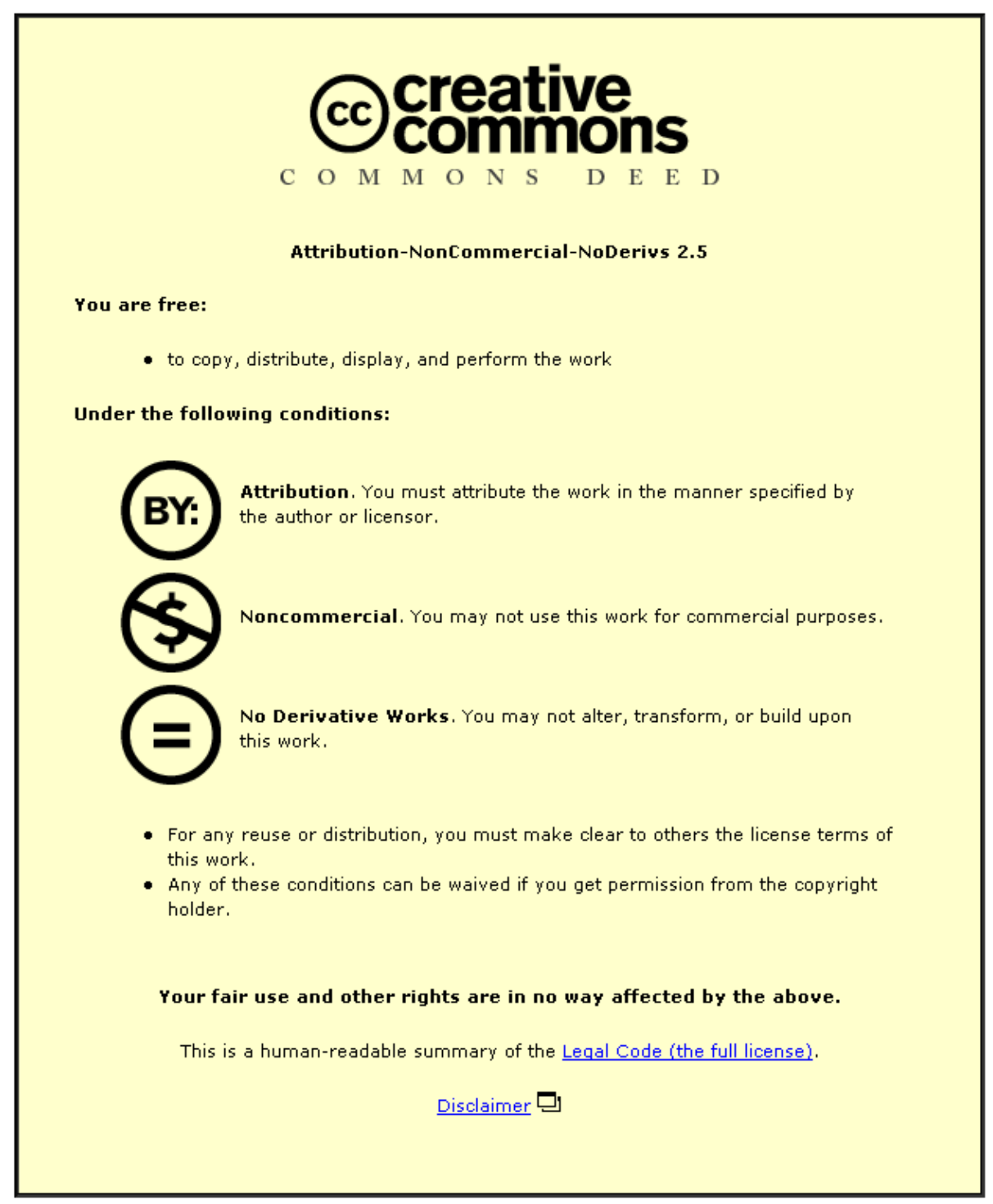

For the full text of this licence, please go to: http://creativecommons.org/licenses/by-nc-nd/2.5/ 


\title{
LOW PRESSURE MICROFILTER DESIGN ASPECTS AND FILTRATION PERFORMANCE
}

Michael Stillwell, Wiwit Sumritwatchasai, Richard Holdich Chemical Engineering, Loughborough University, Loughborough, LE11 3TU, UK.

Serguei Kosvintsev

Micropore Technologies Ltd, Epinal Way, Loughborough, LE11 3EH, UK.

\begin{abstract}
A microfilter should retain micron sized material yet provide minimal resistance to liquid flow. A slotted pore surface microfilter was oscillated whilst filtering yeast cells under constant rate. At shear rates over $7760 \mathrm{~s}^{-1}$, a pore blocking model fitted the data. The operating pressure was very low $(<1000 \mathrm{~Pa})$, but particle retention was limited by the 4 micron pore slot width. A sintered glass micro-bead coating improved yeast rejection: $95 \%$ at 1.7 microns at a shear rate of $5000 \mathrm{~s}^{-1}$, with a $1.2 \mathrm{kPa}$ transmembrane pressure. Two models were validated to assist with the design of future micro-bead coatings constructed from spherical particles.
\end{abstract}

\section{KEYWORDS}

Surface Filtration, Blocking Filtration, Yeast, Fouling, Composite Coating 


\section{INTRODUCTION}

Filtration is a compromise: good particle retention is required, but the resistance to filtrate flow should be low. One method to provide high filtration flux and reliable particle retention is to use surface filters, which are similar in operation to sieves but with a much lower pore size than the conventional sieve range. A surface microfilter has no internal pore structure, thus eliminating irreversible fouling within the membrane. This contrasts with conventional microfiltration membranes where their particle retention capability is provided by a tortuous pore flow channel to capture the particles, at least whilst filtering low concentrations of suspended material that do not form a surface deposit. It is possible to obtain metal surface microfilters $(1,2)$, which are strong and capable of withstanding aggressive mechanical conditions, but the minimum pore size of these filters is limited to a slot width of 4 microns. An example of the filter is illustrated in Figure 1, which illustrates the slotted pores, where each pore forms a direct channel of uniform size from one side of the membrane to the other.

As there is no internal pore structure, irreversible internal membrane fouling is eliminated and, therefore, only requires adequate surface shear to minimise reversible fouling on the surface. This system has been tested in a variety of industrial separations including oil/water filtration and fractionation of highly viscous latex suspensions $(1,3)$.

Other possible industrial areas of interest are in the harvesting of mammalian cells, which are approximately 10 microns in size, and the clarification of rough beer, where spent yeast is separated from the beer without removing material essential for taste 
and colour. In order to improve process efficiency, conventional microfilters with tortuous pore channels are already being introduced to the brewing industry, replacing the traditional filtration method using diatomaceous earth (4-6). Surface microfilters based on silicon nitride have been used to filter bovine serum albumin suspensions (7). However, due to their fragile nature and high manufacturing cost, they have a limited large-scale application and surface adsorption fouling is a significant problem.

The minimum pore size of the metal surface filters, which are available in filtration modules that can be up to one metre in length, is 4 microns. This may be acceptable for the filtration of mammalian cells, but is close to the primary particle size when filtering yeast cells. Hence, to ensure good retention of particles one possibility is to sacrifice the benefits of a surface filter, by providing a thin filtering layer of sintered particles to act as the filtration layer, supported by the strong metal surface filter now acting simply as a mechanical support for the filtration layer. A thin filtration layer can be formed from the material being filtered: it forms a so-called 'dynamic membrane' on the original membrane surface, which can then capture the finer particles that would otherwise penetrate the membrane pores and possibly enter the permeate. However, the physical properties of the dynamic layer, such as thickness and porosity, depend entirely on the process conditions and thus it is hard to fully control (5). In addition, the layer is lost during a cleaning cycle, which has a detrimental effect on the permeate quality immediately afterwards.

This concept of depositing an active layer on top of a surface membrane has been reported recently for a rotating/vibrating filtration system, where a metallo-ceramic 
membrane was created from a stainless steel coarse support with a ceramic selective top layer (6). The resulting nominal pore sizes of between 1-3 microns appeared to achieve $100 \%$ rejection of yeast cells from rough beer samples, suggesting that a target pore size of 1 micron should be the aim for yeast cell filtration. Hence, methods to achieve the aim of 1 micron pore size can be based on modelling of particle packing and properties of the material used to make this coating filtration layer. The properties of porous structures created using glass micro-beads have been reported $(8,9)$ and post-treatment techniques may be applicable in order to minimise microbial adhesion and surface adsorption (10).

Some important considerations in designing the composite membrane include an awareness of how the performance, in terms of flux and rejection, can lead to opposing physical requirements from its structure (11). For example, to maximise the coating's mechanical strength, the porosity must be low and the coating thickness high. This favours increased rejection, but has a negative effect on the permeate flux, and other parameters such as permeability, transmembrane pressure and membrane cleaning. In this case, the coating thickness is just as important as achieving $100 \%$ yeast cell rejection. Whilst a thin coating will maintain the benefits of the original surface membrane, including high flux and permeability, a thicker coating will provide additional strength.

In the work reported here, yeast microfiltration tests have been performed to investigate a bench-scale oscillating system using the metal surface membrane media in a tubular arrangement, in the absence of a sinter surface filtration coating. The membrane's performance was assessed in terms of yeast particle rejection and 
the value of the critical flux. This is the as-received behaviour of the slotted surface microfilters. A mathematical model for blocking filtration was applied, to confirm that the filtration performance was determined by the filtration membrane, and not by a dynamic filtration layer. Under experimental operation at low shear, a filtration deposit did occur, and the blocking model was no longer relevant under these conditions. However, under conditions of high shear the model was appropriate and the filtration performance for the slotted filters is determined by the membrane itself. This indicated the high flux, low pressure performance, but poor retention of yeast cells down to 1 micron in particle size. To provide better filtration performance with the yeast further tests were performed using coated surface membranes, where the original surface filter just provides a low-pressure mechanical support. The intention of this work was to provide a theoretical background to what is required from the particle properties making up the sinter layer, in order to achieve 1 micron filtration pores on-top of the mechanical support from the surface filter.

\section{THEORETICAL ASPECTS}

In a dilute system operating under high shear conditions, fouling of a surface filter is likely to occur primarily via a pore blocking mechanism. As such, a pore blocking model is presented here for constant rate filtration, which was derived from a model originally proposed for constant pressure filtration (12), and adapted to provide filtration resistances and to show liquid viscosity explicitly. The model is based on a sieve mechanism that takes into account the membrane pore size and particle size probability distribution functions, and is shown in Equation 1.

$$
\Delta P=\frac{\mu R_{o}}{(1-y . \text { c.J.t })} J
$$


where $J$ is the permeate flux $\left(\mathrm{m}^{3} \mathrm{~m}^{-2} \mathrm{~s}^{-1}\right.$ in SI units, but later reported in conventional filtration units of litres per square metre of membrane surface per hour), $R_{o}$ is the initial membrane resistance $\left(\mathrm{m}^{-1}\right), \Delta P$ is the transmembrane pressure $(\mathrm{Pa}), y$ is the blocking area $\left(\mathrm{m}^{2} \mathrm{~kg}^{-1}-\right.$ of dry material), $c$ is the concentration of the suspension ( $\mathrm{kg}$ $\mathrm{m}^{-3}$ ) and $t$ is the filtration time (s).

If filtration performance, in terms of particle rejection, is not adequate from a surface filter then a porous matrix type of deposit will be needed for filtration that consists of a thin layer of spherical particles. Equation 2 can be used to calculate the hydraulic mean diameter of a flow channel through a packed bed of spherical particles, which represents a theoretical mean pore size (13).

$$
d_{H}=\frac{\bar{\varepsilon}}{(1-\bar{\varepsilon}) S_{V}}
$$

where $d_{H}$ is the hydraulic mean diameter $(\mu \mathrm{m}), \varepsilon$ is the average bed porosity and $S_{V}$ is the specific surface of the glass beads used to form the coating.

Equation 3 was proposed to estimate the average bed porosity $(\varepsilon)$ of randomly packed solid spherical particles of various sizes (14):

$$
\bar{\varepsilon}=1-\frac{\sum_{i=1}^{m} D_{i}^{3} f_{i}}{\sum_{i=1}^{m}\left(D_{i}-\bar{D}\right)^{3} f_{i}+\frac{1}{n} \sum_{i=1}^{m}\left(\left(D_{i}+\bar{D}\right)^{3}-\left(D_{i}-\bar{D}\right)^{3}\right) f_{i}}
$$


where $D_{i}$ is the particle diameter of the $i^{\text {th }}$ component based on a size range (or grade) within the size distributed solids, $f_{i}$ is the fractional number of the $i^{\text {th }}$ component and $\bar{D}$ is the average particle diameter from the size distribution. The parameter $\bar{n}$ represents the number of hypothetical particles surrounding a central particle within the packing, and is calculated from the particle size distribution.

\section{MATERIALS \& METHODS}

\subsection{Yeast Challenge Suspensions}

The yeast challenge suspensions for all the studies were prepared at a concentration of $0.1 \mathrm{~g} / \mathrm{l}$ by dispersing cylindrical pellets of readily available dried baker's yeast (Allinson, UK) into ultra-pure water from a Milli-Q Plus 185 ultra pure water system. Each suspension was freshly made prior to testing and was agitated with a magnetic stirrer in order to reduce the number of cell aggregates. This was verified using an optical microscope. A typical suspension had an average size of 4.3 microns, and contained no particles larger than 13.0 microns. All particle size distributions were obtained using a Coulter Multisizer.

\subsection{Oscillating Filtration System}

An oscillating filtration system was provided by Micropore Technologies Ltd. (Leicestershire, UK) with a tubular metal surface membrane. The membrane had an active area length of $65 \mathrm{~mm}$ and diameter $14 \mathrm{~mm}$, and contained slotted pores 400 microns long by 6 microns wide (Figure 2). 
Due to the width of the slotted pore, $100 \%$ particle rejection could be achieved down to a size of 6 microns. The tubular membrane was attached to an electrically driven vertical oscillator, and was immersed in the yeast feed suspension. The yeast suspension was gently agitated using a magnetic stirrer. The magnitude of the shear generated at the membrane surface was controlled through changes to the frequency and/or amplitude of the oscillation, with frequencies between 10-40 $\mathrm{Hz}$ and amplitudes of $0.5-3.0 \mathrm{~mm}$. The membrane was supplied with a durable low surface energy coating of PTFE, in order to minimise any adhesion of the yeast cells. The permeate was drawn through the membrane pores using a peristaltic pump, and then recycled back to the feed suspension. The recycle line was also used to obtain samples for flux and rejection measurements. The transmembrane pressure was measured using a water manometer located on the permeate side, upstream of the peristaltic pump. All equipment was thoroughly rinsed using ultra-pure water following each test. The membrane was cleaned inside an ultrasonic bath and was subjected to a clean water flux test to ensure its cleanliness.

The effect of increasing the shear rate on the critical flux and membrane rejection was investigated. When operating below the critical flux, membrane surface fouling occurs at a low rate so that changes in the transmembrane pressure over time are low (15). When operating above the critical flux, membrane fouling occurs at a faster rate, with potentially a sudden large increase in the transmembrane pressure. The critical flux was identified in this work as the point at which a significant deviation occurred from the flux characteristics of ultra-pure water. The steady state permeate flux was determined at each pump setting by recording the time taken to collect $20 \mathrm{ml}$ of permeate in a measuring cylinder that was placed on an electronic balance. The 
pressure readings at each pump setting were manually logged every thirty seconds from the pressure measurement system upstream of the peristaltic pump on the permeate side.

The particle rejection was calculated using the size distribution data for permeate samples taken below the critical flux at each shear rate. This was to avoid filtration being performed through a dynamic, or secondary, membrane which would improve the reported rejection of the surface membrane. The amount of yeast particles present in the permeate sample were compared to the amount present in the original feed. This is defined mathematically, as a percentage, in Equation 4.

$$
\text { Rejection }=\left(1-\frac{\text { mass of particles in the permeate grade }}{\text { mass of particles in the feed grade }}\right) \times 100
$$

\subsection{Coated Surface Membranes}

A series of sintered particulate coatings were tested in order to enhance the rejection of the smaller yeast particles. The coatings were prepared by sintering glass microbeads of different sizes onto a $42 \mathrm{~mm}$ diameter flat circular disc surface membrane support, which provided high strength and low resistance. The support had slotted pore dimensions of 35 microns width and 800 microns length to ensure that no filtration could be attributed to the support layer.

Ballotini glass beads with a mean particle size of 20 microns were obtained from Jencons Scientific Ltd, UK for initial testing, followed by a smaller grade with a mean size of 6.8 microns from Particle Technology Ltd, UK. A controlled quantity of glass 
beads was manually deposited onto the support, which was then sintered for a range of temperatures, times and pressures using a Carbolite furnace with a Eurotherm temperature controller. The optimum sintering conditions were outlined based on visual observations and optical microscope images of the sintered coatings. Crosssectional images of the best coatings were obtained using a Cambridge Instruments Stereoscan 360 scanning electron microscope to confirm the extent of particle softening and the existence of interstitial void spaces for fluid flow.

The sintered composite membranes were inserted into a Micropore Technologies Ltd. dead-end stirred cell filtration device to determine the clean water membrane resistance and permeability using Darcy's equation. The coated membranes were then subjected to constant permeate flux yeast filtration studies to determine critical flux and yeast rejection. The flux, pressure and rejection data were recorded at three different pump settings, starting with the lowest setting. The flux was determined by weighing the amount of permeate obtained within a measured amount of time. Permeate samples were taken for particle size analysis, allowing the yeast particle rejection to be calculated in the same way as for the oscillating system. The transmembrane pressure was measured using a mercury manometer, located on the permeate side. The maximum shear rate at the membrane surface for all filtration studies was approximately $5000 \mathrm{~s}^{-1}$ using an electrically driven paddle stirrer. The shear was calculated using previously reported equations for a stirred cell geometry (16).

The membrane pore size distribution was measured with a PMI Automated Capillary Flow Porometer, using a PMI standard tortuosity value of 0.715 . The porosity of a 
packed bed of glass beads was calculated by adding a known mass of dry glass beads into a measuring cylinder and noting the volume occupied by the bed. The calculation required an experimentally determined glass bead density, which was measured using a Micromeritics Multi-Volume Pycnometer 1305 with glass bead samples dried overnight in a vacuum oven at $75^{\circ} \mathrm{C}$. The density was found to be $2440 \mathrm{~kg} \mathrm{~m}^{-3}$. The validity of equations 2 and 3 were tested, so that they may be used to aid the design of future coatings.

\section{RESULTS \& DISCUSSION}

\subsection{Oscillating System}

From the yeast filtration studies, the critical flux was found to increase with increased shear rate at the membrane surface. At the lowest shear rate of $249 \mathrm{~s}^{-1}$ and the highest shear rate of $7761 \mathrm{~s}^{-1}$, the critical fluxes were $90 \mathrm{I} \mathrm{m}^{-2} \mathrm{hr}^{-1}$ and $1000 \mathrm{I} \mathrm{m}^{-2} \mathrm{hr}^{-1}$ respectively. During filtration, the fouling layer of yeast particles that built up on the membrane surface was limited by the oscillatory shear. This shear pattern generates a peak shear twice during one cycle, between the maximum positive and negative amplitudes. A higher amplitude and frequency creates a larger peak shear, which helps to keep the membrane surface cleaner, and therefore increases the critical flux.

Figure 3 shows the yeast rejection data obtained at the lowest and highest shear rates with a nominal 4 micron slotted filter, for permeate samples taken below their critical fluxes.

The best rejection curve was obtained at the lowest shear rate, with $100 \%$ rejection around 6 microns. At the smaller particle sizes of between 1-2 microns, the rejection 
falls to around $50 \%$. At the highest shear rate, the rejection curve deteriorates with $0 \%$ rejection for particle sizes below approximately 2.5 microns. This is the true rejection curve for this particular membrane, because under higher shear conditions there is little, or no, secondary membrane to enhance the rejection, as is observed for the lowest shear rate.

In order to test the predictions of Equation 1, the transmembrane pressure data was plotted as a function of time for all shear rates. In Figure 4(a), the shear rate is high and the pore blocking model corresponds well to the experimental data: indicating that under these conditions the microfilter does not have a secondary membrane formed and the rejection data is due to the filtration membrane alone. Hence, the rejection curve shown in Figure 3, for a shear rate of $7761 \mathrm{~s}^{-1}$, is a characteristic of this membrane filtering with this concentration of suspended solids. In Figure 4(b) the surface shear rate is low, the pore blocking model does not fit the data, and it can be concluded that a secondary membrane has formed apparently increasing the transmembrane pressure (above a pore blocking model) and leading to the enhanced particle rejection illustrated in Figure 3 (at $249 \mathrm{~s}^{-1}$ ). For all of these tests the average permeate flux $\mathrm{J}$ was $630 \mathrm{I} \mathrm{m}^{-2} \mathrm{hr}^{-1}$, and the solids concentration $c$ was $0.71 \mathrm{~kg} \mathrm{~m}^{-3}$

These results demonstrate the importance of using an adequate shear rate to obtain a larger, more productive, critical flux. However, the coarse membrane pore size and absence of a cake layer at a high shear rate decreases the rejection of small particles (sub four microns). 


\subsection{Sintered Composite Membranes}

In order to improve the rejection of smaller particles, composite membranes consisting of a surface filter support with a sintered glass bead active layer, were prepared. Composite membranes A, B and C were sintered under different conditions as shown in Table 1.

Membrane A was sintered at double the pressure used to sinter membranes $B$ and C. Figure 5 is a cross-sectional view through membrane $\mathrm{A}$, which indicates that the glass microspheres were adequately softened to form a single robust coating, with interstitial void spaces for the permeate to flow. This was observed for all three membrane cross-sections.

Although the glass beads had an average diameter of 20 microns, the sample distribution was quite wide and contained beads up to 70 microns in diameter. The presence of the larger beads created larger interstitial void spaces around them, compared to those spaces formed around the smaller beads.

The transmembrane pressure and permeate flux data from the dead-end yeast filtration test for membrane A are shown in Figure 6 , which were virtually identical to the data obtained for membranes B and C.

At the lowest permeate rate, a constant low transmembrane pressure of $1.2 \mathrm{kPa}$ and a permeate flux of approximately $120 \mathrm{I} \mathrm{m}^{-2} \mathrm{hr}^{-1}$ were maintained for 140 minutes. At the next highest permeate rate, a steadily increasing pressure was observed due to an increased rate of internal membrane fouling. This was clearly the case when the 
permeate rate was increased further. The critical flux appeared to be in the region between $120-300 \mathrm{I} \mathrm{m}^{-2} \mathrm{hr}^{-1}$, which is within the target region for new membrane developments in today's brewing industry, where flux values above $100 \mathrm{I} \mathrm{m}^{-2} \mathrm{hr}^{-1}$ are desired (6). Larger fluxes could potentially be achieved using either a cross-flow or oscillating system, operating at a higher shear rate.

Figure 7 compares the yeast particle rejection curve for membrane $A$ to the rejection curve of the non-coated membrane used in the oscillating yeast filtration system at the highest shear rate of $7761 \mathrm{~s}^{-1}$.

It is clear to see that the membrane coating significantly improved the filtration performance, with a rejection of over $90 \%$ down to a particle size of 1.7 microns. Particle rejection values below this size could not be obtained due to limitations with the size analysis equipment. The rejection curves for membrane $A$ at each of the three pump settings were consistent, and demonstrated slightly higher rejection values than for membranes $B$ and $C$. This was due to the higher pressure used in the sintering process, which created a larger number of smaller pores. Optical micrographs of the permeate samples for membrane A showed that only a handful of yeast cells were present, which fell within the reported range of 1-10 cells $/ \mathrm{ml}$ for good quality filtered beer (6). The small particles detected by the size analysis equipment could be debris resulting from damaged cells during the filtration test.

The membranes were also extremely permeable, with the lowest value obtained for membrane A of $9.4 \times 10^{-14} \mathrm{~m}^{2}$, which had the highest degree of sintering. In contrast, track-etched and polycarbonate membranes have much lower permeabilities of 
$0.027 \times 10^{-14} \mathrm{~m}^{2}$ and $0.004 \times 10^{-14} \mathrm{~m}^{2}$ respectively (11). The clean water resistance of membrane A was correspondingly low at $8.0 \times 10^{9} \mathrm{~m}^{-1}$, which is a slight improvement on the clean water resistance of $10.0 \times 10^{9} \mathrm{~m}^{-1}$ for the metallo-ceramic membrane reported in (6) for yeast filtration. After the filtration and a simple washing procedure using ultra pure water in an ultrasonic bath, the permeability values decreased due to internal fouling by captured yeast particles. However, the permeability values were still relatively high at $4.0 \times 10^{-14} \mathrm{~m}^{2}$, which demonstrates their ability to be reused.

\subsection{Alternative Coating Designs}

In order to minimise the extent of internal fouling and enhance cleaning, a custom made device was fabricated to deposit a uniform thin layer of dry glass microspheres. However, as the sintered coating operates via a depth filtration mechanism and the thickness of the coating was to be reduced, it was also necessary to use smaller glass beads in the coating to maintain, and improve upon, the current yeast rejection. Several different grades of glass bead were obtained by settling the existing batch of beads (non-graded) in a water/glycerol solution. After a set time, the top liquid was removed to capture the desired smaller non-settled beads. Table 2 contains the key particle size data for two of the different grades of bead obtained via settling. Grade 3 was supplied from Particle Technology Ltd., UK.

Membrane $\mathrm{D}$ was prepared from a thin layer of Grade 2 beads deposited on top of a layer of non-graded beads, to produce a total coating thickness of 440 microns. The active layer containing the finer Grade 2 beads was therefore expected to capture the majority of the particles, whilst the coarser beads provided additional strength. Membrane $D$ was then exposed to a yeast filtration test using the same procedures described previously. The yeast particle rejection curve is shown in Figure 8, for 
permeate samples taken at a flux of $120 \mathrm{I} \mathrm{m}^{-2} \mathrm{hr}^{-1}$ and a constant transmembrane pressure below $1.0 \mathrm{kPa}$.

The rejection curve of membrane $D$ was very similar to that of membrane $A$, which is an encouraging result; as there was a reduction in coating thickness by a factor of 1.7. This demonstrated the effectiveness of using smaller beads coupled with a thinner coating.

\subsection{Coating Design Equations}

The benefit of using smaller glass beads is demonstrated in Figure 9, which shows how the predicted hydraulic mean diameter from equation 2 varies with the average bed porosity for the bead grades listed in Table 2. The porosity predictions of equation 3 were found to be in good agreement with the measured data.

The predicted hydraulic mean diameter (now referred to as the pore size) of the nongraded beads was calculated as 3.2 microns, using an experimentally determined average bed porosity of 0.38 . This value compares well to a median pore size of 3.0 microns obtained using a PMI porometer, and to the yeast rejection data where $97 \%$ of particles of size 3.2 microns were rejected. This indicates that the model predictions, based on equations 3 and 2, appear reasonable. It has been reported that the optimum pore size for yeast filtration is 1-3 microns, in order to remove sufficient yeast cells and obtain good permeate clarity, whilst retaining materials essential for taste (6). Slight changes to the membrane sintering conditions could therefore be made in order to meet the required beer clarity standards. 
In addition to using smaller bead grades, Figure 9 shows how porosity reduction through controlled sintering conditions can be used to achieve the objective pore size of 1.0 micron. It is therefore possible to theoretically achieve a $100 \%$ rejection of yeast cells using Grade 3 beads. At the objective pore size, the resulting sintered bed will have a relatively higher porosity than a sintered bed made from the larger bead grades, which is beneficial for microfiltration.

\section{CONCLUSIONS}

Metal surface membranes provide the benefits of low operating costs and greater process efficiency through low membrane resistance and high permeate flux. The aim of this paper was to investigate the operational characteristics and performance of a these surface filters against yeast suspensions. A tubular surface filter was connected to an oscillating unit, to provide the surface shear, and subjected to a constant rate filtration process. The critical flux was found to increase with increased shear rate, but the yeast rejection decreased, due to the removal of the fouling cake layer (secondary membrane) at the higher shear rate. When operating below the critical flux $\left(630 \mathrm{I} \mathrm{m}^{-2} \mathrm{~h}^{-1}\right)$ for fouling layer deposition at shear rates above $4225 \mathrm{~s}^{-1}$, the rate of membrane fouling was in good agreement with the proposed poreblocking model for a constant rate filtration, which supports the belief that there was insignificant secondary membrane formation and the true particle rejection capability of the surface microfiltration membrane can be obtained from this data.

In order to improve the particle rejection ability of the membrane at the higher shear rates, surface membranes were coated with glass beads and sintered under a range of conditions. A significant improvement was obtained, with $95 \%$ rejection of particles with diameters down to 1.7 microns at a shear rate of $5000 \mathrm{~s}^{-1}$. The initial 
membrane permeability was high at $9.4 \times 10^{-14} \mathrm{~m}^{2}$, with a critical flux suitable for industrial yeast cell filtration of at least $120 \mathrm{I} \mathrm{m}^{-2} \mathrm{hr}^{-1}$ at a transmembrane pressure of only $1.2 \mathrm{kPa}$. Despite some fouling within the internal sintered structure, the membrane permeability remained high at $4.0 \times 10^{-14} \mathrm{~m}^{2}$ following a yeast filtration and simple wash with ultra-pure water. Yeast cells have been found to adhere weakly to the glass beads, but a variety of low surface energy coatings are available for glass that may help reject the components present in rough beer that would otherwise be expected to adhere strongly to the surfaces. Two functional models were tested against experimental data to aid in the design of similar particulate-based coatings in the future, with the aim of achieving a sintered 1 micron pore size membrane; consisting of a thin coating of beads on top of a thin strong mechanical support made from the slotted microfiltration media. The models predicted a pore size of 3.2 microns, which compared well to a median pore size of 3.0 microns obtained using a PMI porometer, and to the yeast rejection data where $97 \%$ of particles of size 3.2 microns were rejected.

By altering the surface membrane in this way, the yeast cells were captured during their passage through the sintered coating and were thus prevented from reaching the slotted pores of the surface membrane support. The design intention was to capture the yeast cells within the top layer, or top few layers of the sintered glass beads, thus minimising the degree of depth filtration that occurred. This would provide the highest permeability and critical flux in keeping with the original surface membrane, which acted solely as a support in this application. The membrane thickness was therefore just as important in this design, as achieving a high yeast 
cell rejection. This could be achieved by depositing an optimal thickness of suitably small glass beads that are sintered under controlled conditions.

\section{ACKNOWLEDGEMENTS}

The authors would like to thank Mr. Chris Manning and Dr. Gilbert Shama of Loughborough University for their help and support with various aspects of this work, and the EPSRC for project funding through the Engineering Doctorate scheme.

\section{REFERENCES}

1. Holdich, R.G., Cumming, I.W., and Kosvintsev, S.R. Slotted pore microfilters for oil/water filtration, fractionation and aggressive filtration environments. Membrane Technology, 2004, 3, 5-10.

2. Baumeister, M., Dickmann, K., Duka, M. and Hoult, T., Microfiltration membranes with straight pore channels formed by high-speed fiber-laser perforation o stainless steel foils. Filtration, 2006, 6, 216-219.

3. Holdich, R. G., Kosvintsev, S. R., and Zhdanov, S. In Tenth World Filtration Congress on Pulsed Flow Microfiltration With a Spiral Wound Membrane, Leipzig, Germany, 14-18 April 2008, Conference Proceedings, Volume II, pp. 330-334.

4. Schenk Filterbau GmbH. Tangential flow filtration for beer recovery from spent yeast. Filtration \& Separation, 1998, 9, 863-865.

5. Al-akoum, O., Mercier-Bonin, M., Ding, L., Fonade, C., Aptel, P., and Jaffrin, M. Comparison of three different systems used for flux enhancement: application to cross-flow filtration of spent yeast suspensions. Desalination, 2002, 1-3, 31-36. 
6. Fillaudeau, L., Boissier, B., Moreau, A., Blanpain-avet, P., Ermolaev, S., Jitariouk, N., and Gourdon, A. Investigation of rotating and vibrating filtration for clarification of rough beer. Journal of Food Engineering, 2007, 1, 206-217.

7. Girones, M., Lammertink, R. G. H., and Wessling, M. Protein aggregate deposition and fouling reduction strategies with high-flux silicon nitride microsieves. J. Membr. Sci., 2006, 1-2, 68-76.

8. Carrasco, M. F., Mendiratta, S. K., and Ferreira, J. M. Strength porosity and permeability of sintered bodies made from glass microspheres. Eur. Phys. J. Appl. Phys., 2005, 2, 91-99.

9. Subero, J., Pascual, D., and Ghadiri, M. Production of agglomerates of welldefined structures and bond properties using a novel technique. Chemical Engineering Research and Design, 2000, 1, 55-60.

10. Picard, C., Larbot, A., Tronel-Peyroz, E., and Berjoan, R. Characterisation of hydrophilic ceramic membranes modified by fluoroalkylsilanes into hydrophobic membranes. Solid State Sci., 2004, 6, 605-612.

11. Wakeman, R. J., Henshall, J. L., and Ng, S. G. Modification of sialon microfilters by pressureless sintering, pyrolysis of organometallic precursors and nitridation of thin films. Chemical Engineering Research \& Design, 1996, A3, 329-339.

12. Filippov, A., Starov, V. M., Lloyd, D. R., Chakravarti, S., and Glaser, S. Sieve mechanism of microfiltration. J. Membr. Sci. 1994, 3, 199-213.

13. Rushton, A., Ward, A.S., and Holdich, R.G. Solid-Liquid Filtration and Separation Technology. VCH, Weinheim, 1996, p34. 
14. Ouchlyama, N., and Tanaka, T. Porosity estimation for random packings of spherical particles. Ind. Eng. Chem. Fundam., 1984, 490-493.

15. Hughes, D., and Field, R. W. Cross-flow filtration of washed and unwashed yeast suspensions at constant shear under nominally sub-critical conditions. Journal of Membrane Science, 2006, 1-2, 89-98.

16. Stillwell, M. T., Holdich, R. G., Kosvintsev, S. R., Gasparini, G., and Cumming, I. W. Stirred cell membrane emulsification and factors influencing dispersion drop size and uniformity. Ind Eng Chem Res, 2007, 3, 965-972. 


\section{LIST OF TABLES}

Table 1 Summary of the sintering conditions used

Table 2 Summary of particle size data for different grades of glass bead 


\section{TABLES}

Table 1 Summary of the sintering conditions used

\begin{tabular}{|c|c|c|c|}
\hline Membrane & $\begin{array}{c}\text { Sinter Temperature } \\
{ }^{\circ} \mathbf{C}\end{array}$ & $\begin{array}{c}\text { Sinter Time } \\
\text { mins }\end{array}$ & $\begin{array}{c}\text { Thickness } \\
\boldsymbol{\mu m}\end{array}$ \\
\hline A & 700 & 60 & 740 \\
\hline B & 700 & 60 & 890 \\
\hline C & 675 & 180 & 740 \\
\hline
\end{tabular}

Table 2 Summary of particle size data for different grades of glass bead

\begin{tabular}{|c|c|c|}
\hline Bead Grade & $\begin{array}{c}\text { Mean Diameter } \\
\boldsymbol{\mu m}\end{array}$ & $\begin{array}{c}\text { Specific Surface } \\
\mathbf{m}^{-\mathbf{1}}\left(\mathbf{\times 1 0 ^ { 5 }}\right)\end{array}$ \\
\hline Non - graded & 20.0 & 1.9 \\
\hline Grade 1 & 16.1 & 2.8 \\
\hline Grade 2 & 10.3 & 3.9 \\
\hline Grade 3 & 6.8 & 6.2 \\
\hline
\end{tabular}




\section{LIST OF FIGURES}

Figure 1 Scanning Electron Micrograph of the metal surface membrane used in this study

Figure 2 Oscillating filtration system with a nominal 4 micron tubular membrane

Figure $3 \quad$ Yeast rejection curves at the lowest and highest shear rates

Figure 4 Pore blocking model predictions in (a) the high shear rate region of $4225-7761 \mathrm{~s}^{-1}$, and (b) the low shear rate region of $249-2817 \mathrm{~s}^{-1}$

Figure 5 Scanning Electron Micrograph cross-section through membrane A

Figure $6 \quad$ Filtration data for Membrane A: transmembrane pressure and flux with filtration time

Figure 7 Comparison of rejection data for membrane $A$ and the non-coated membrane under conditions when no secondary membrane occurs

Figure 8 Comparison of yeast rejection curves for membranes A and D: both sintered coating membranes but different coatings thickness and size of sinter particles

Figure 9 Predicted hydraulic mean diameters through a particulate bed for the available sizes of glass beads and different sintered bed porosities 


\section{FIGURES}

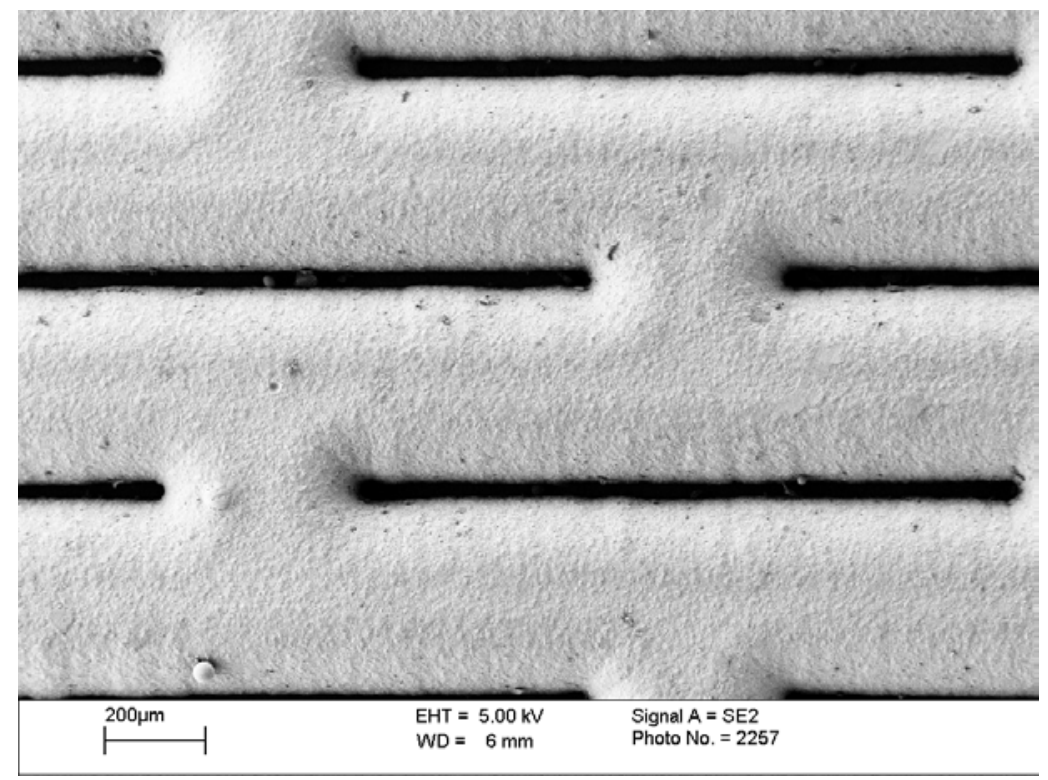

Figure 1 Scanning Electron Micrograph of the metal surface membrane used in this study 
Slotted pore membrane medium

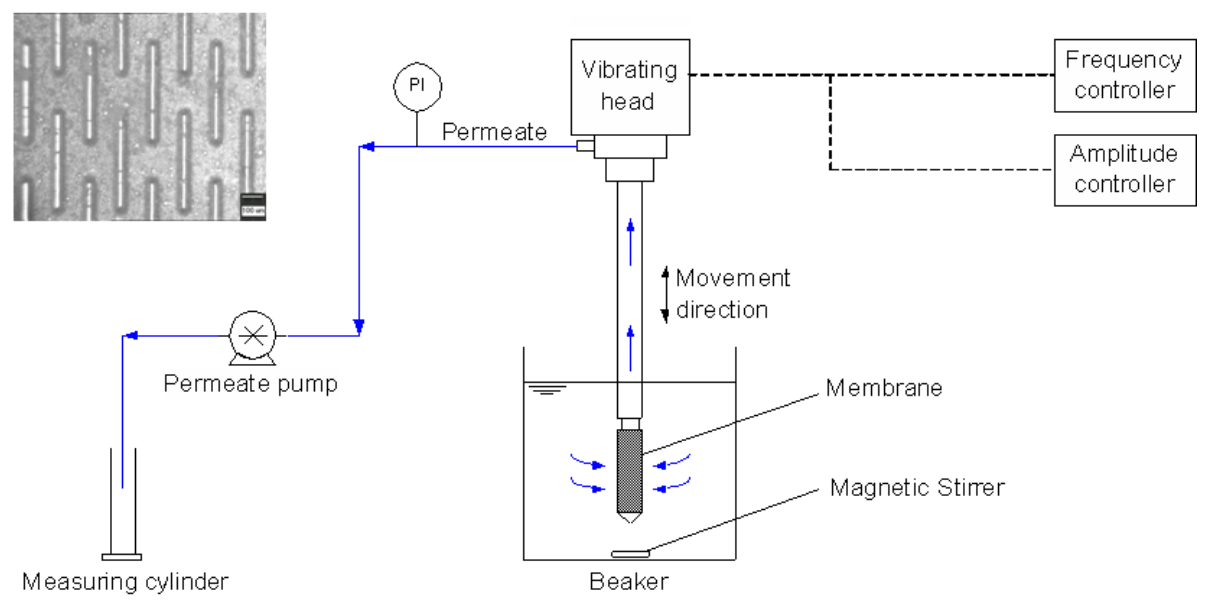

Figure 2 Oscillating filtration system with a nominal 4 micron tubular membrane 


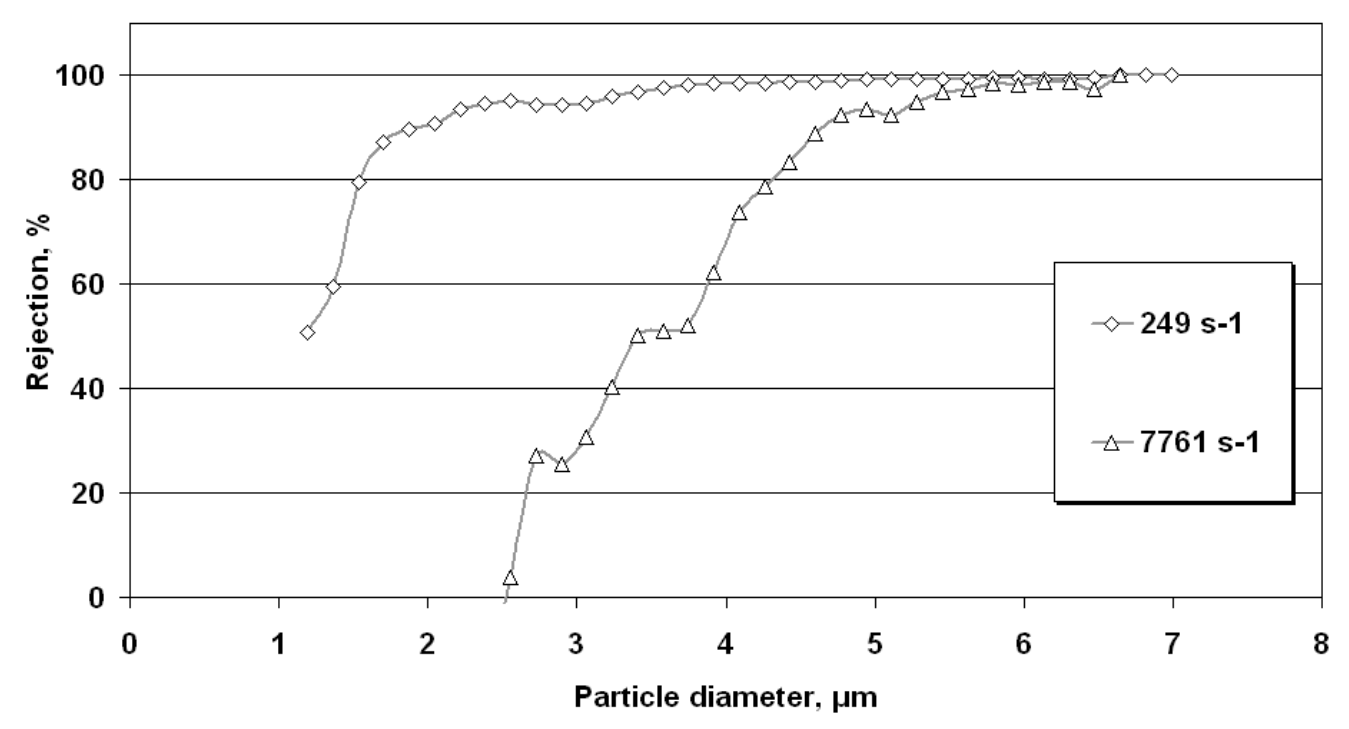

Figure 3 Yeast rejection curves at the lowest and highest shear rates 


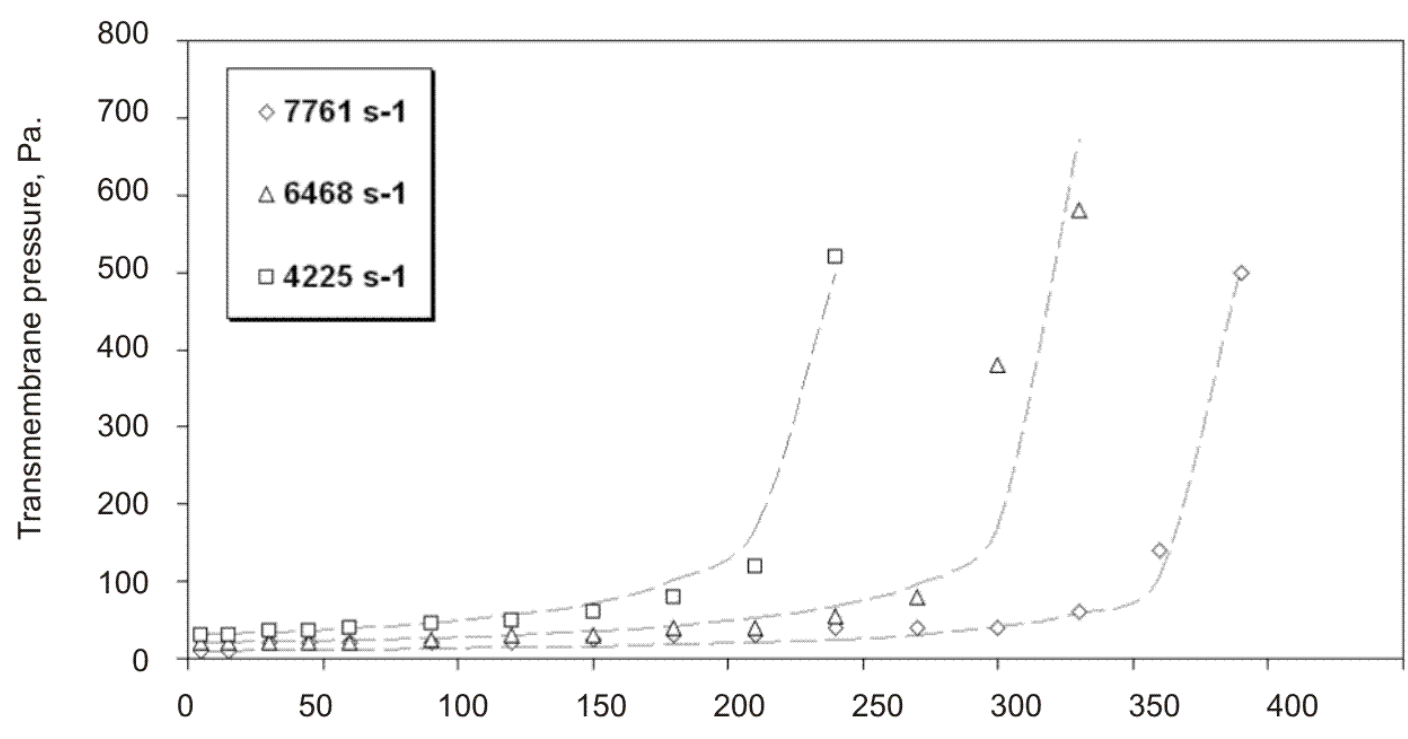

Filtration time, s.

(a)

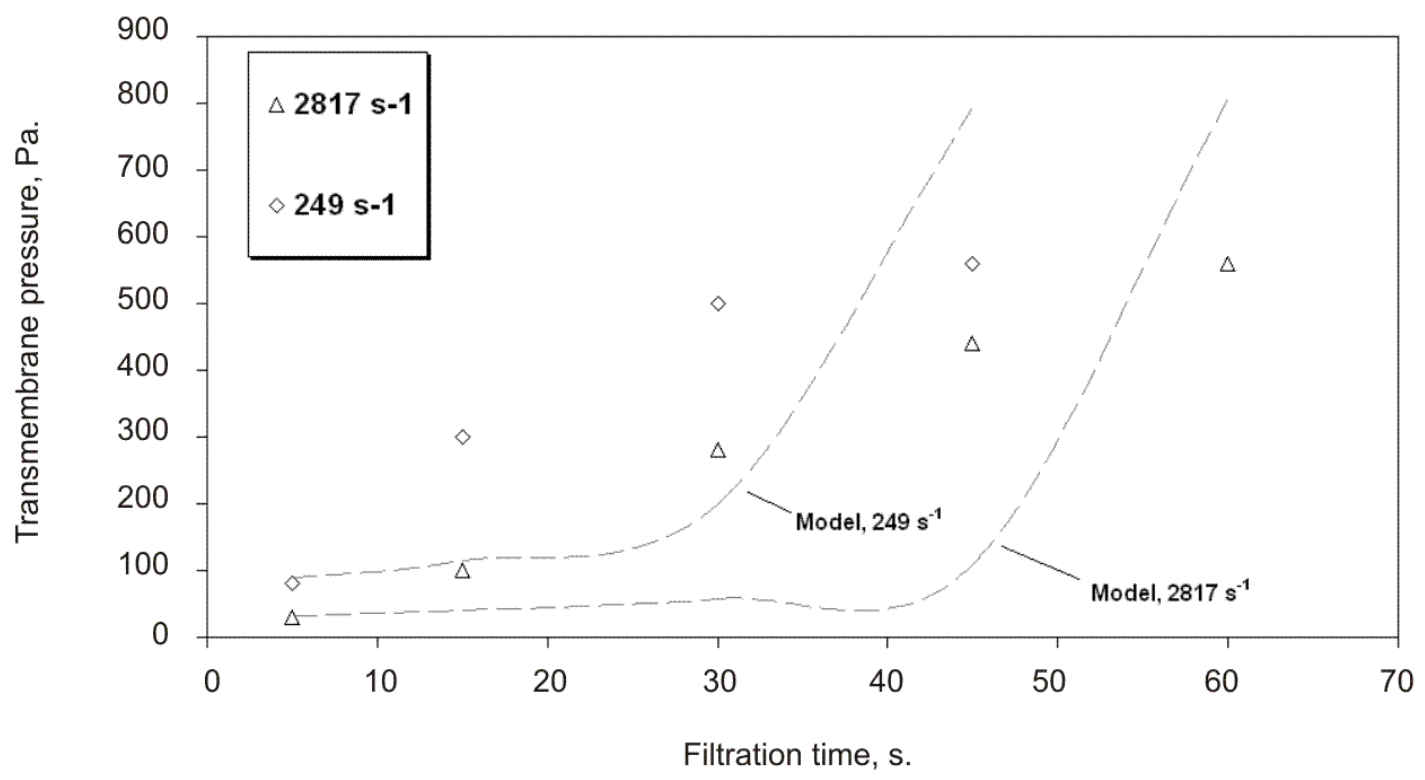

(b)

Figure 4 Pore blocking model predictions in (a) the high shear rate region of $4225-7761 \mathrm{~s}^{-1}$, and (b) the low shear rate region of $249-2817 \mathrm{~s}^{-1}$ 


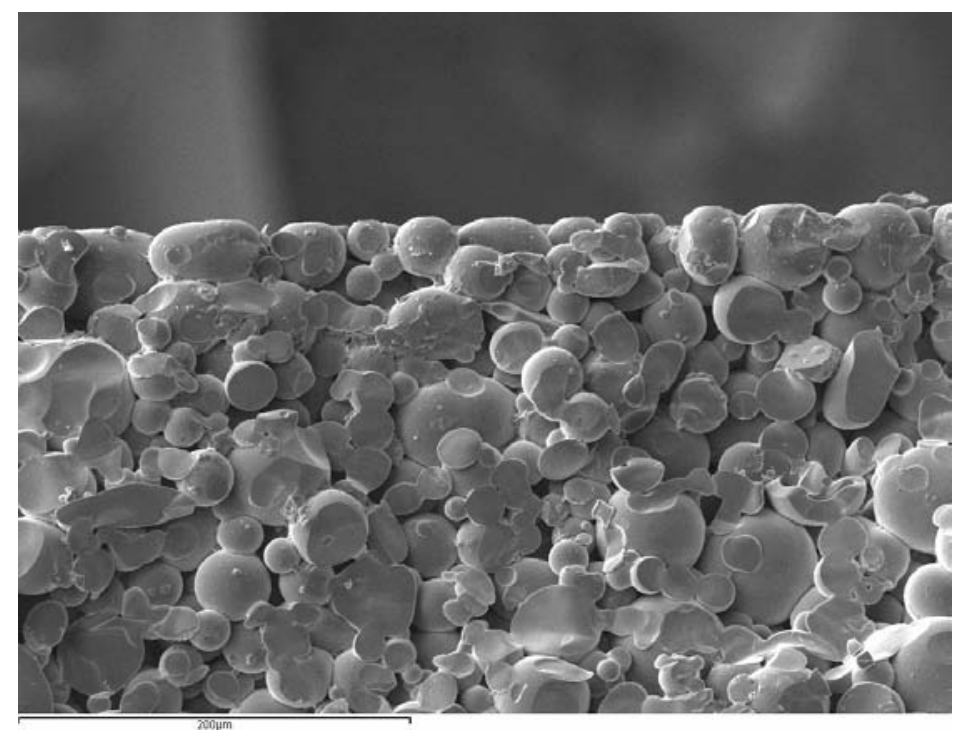

Figure 5 Scanning Electron Micrograph cross-section through membrane A 


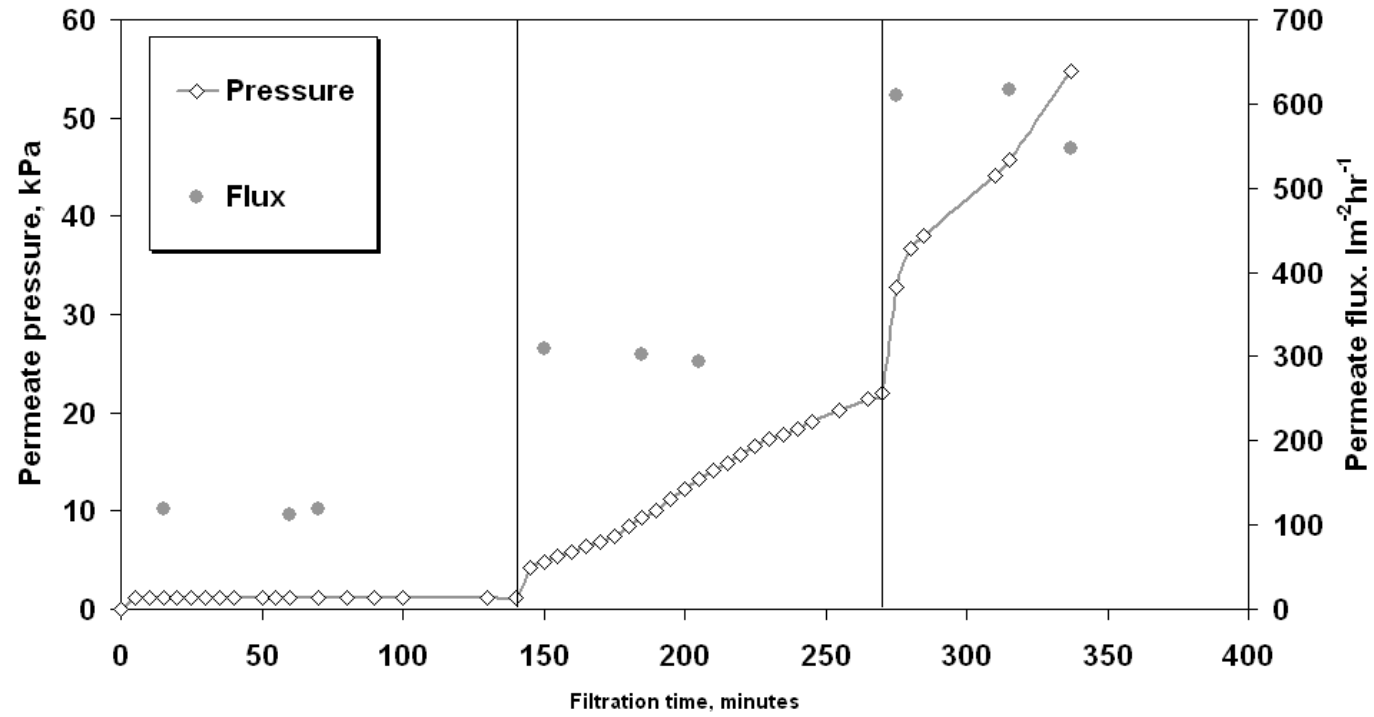

Figure $6 \quad$ Filtration data for Membrane A: transmembrane pressure and flux with filtration time 


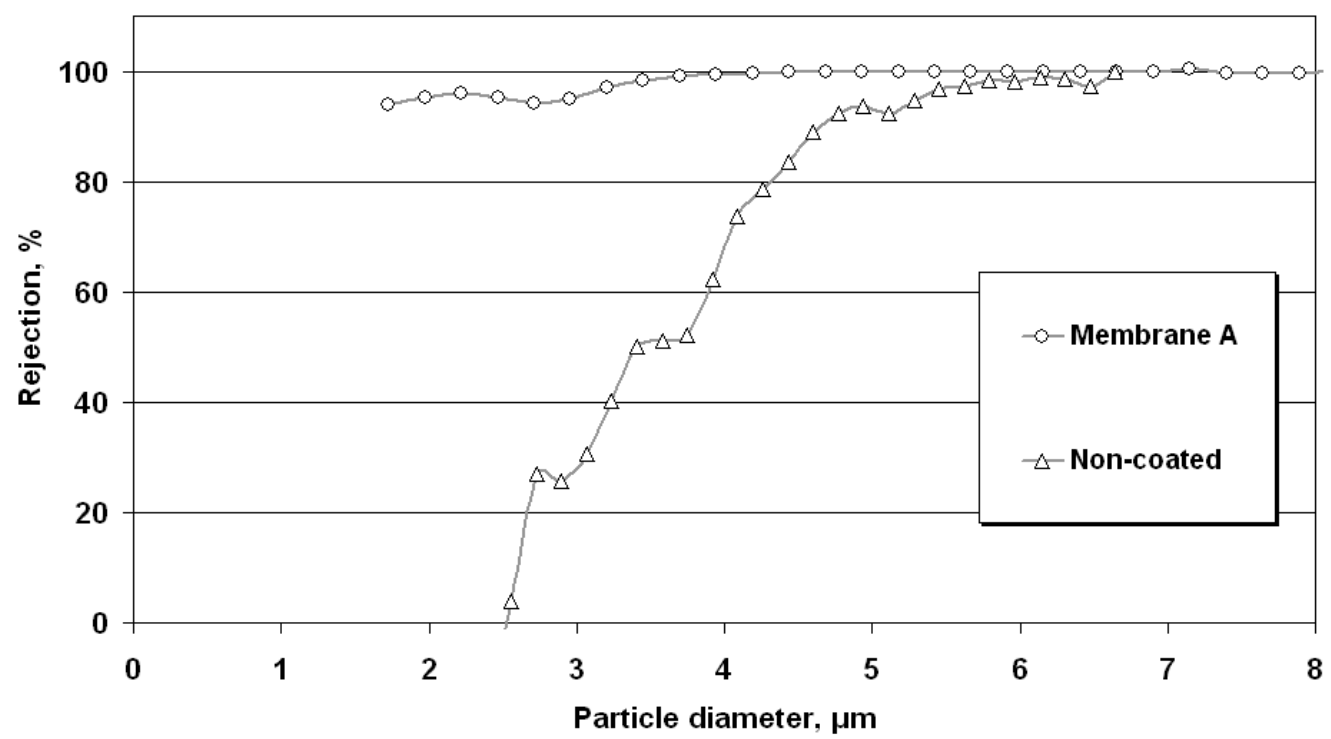

Figure 7 Comparison of rejection data for membrane $A$ and the non-coated membrane under conditions when no secondary membrane occurs 


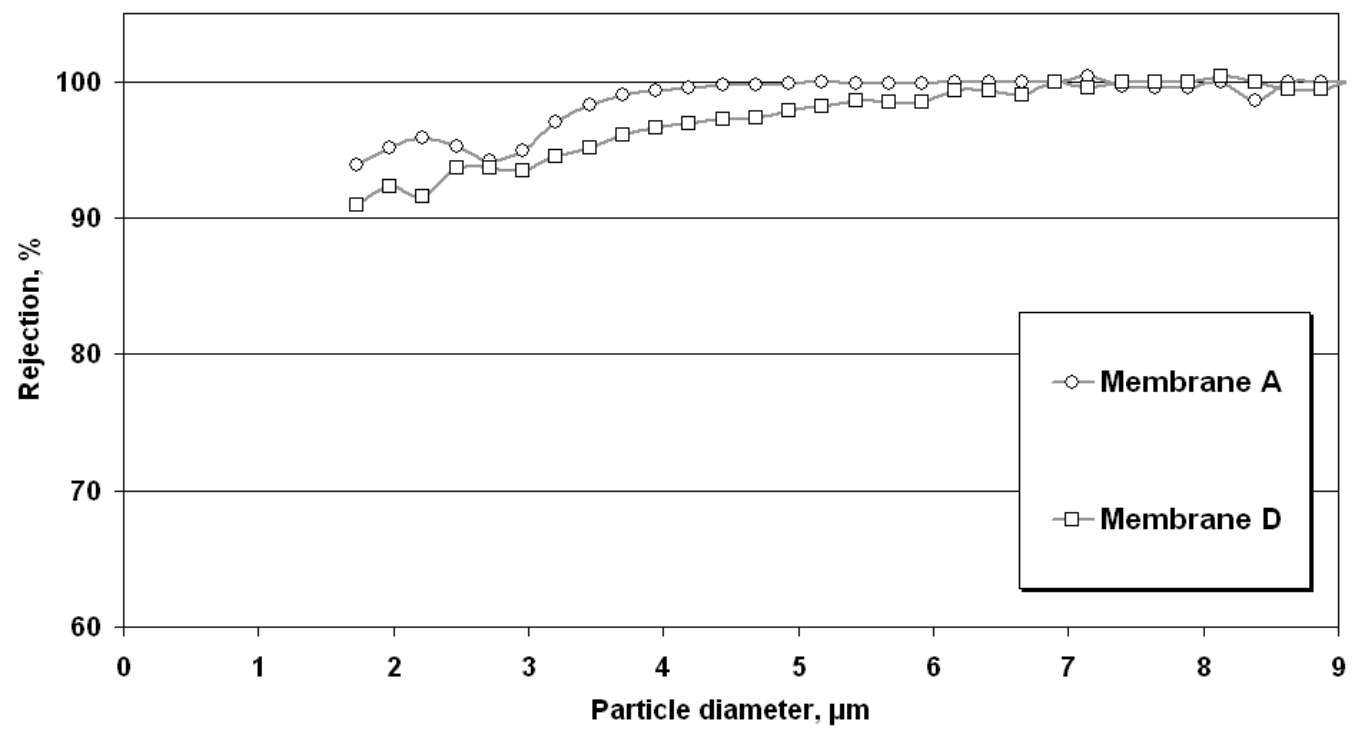

Figure 8 Comparison of yeast rejection curves for membranes A and D: both sintered coating membranes but different coatings thickness and size of sinter particles 


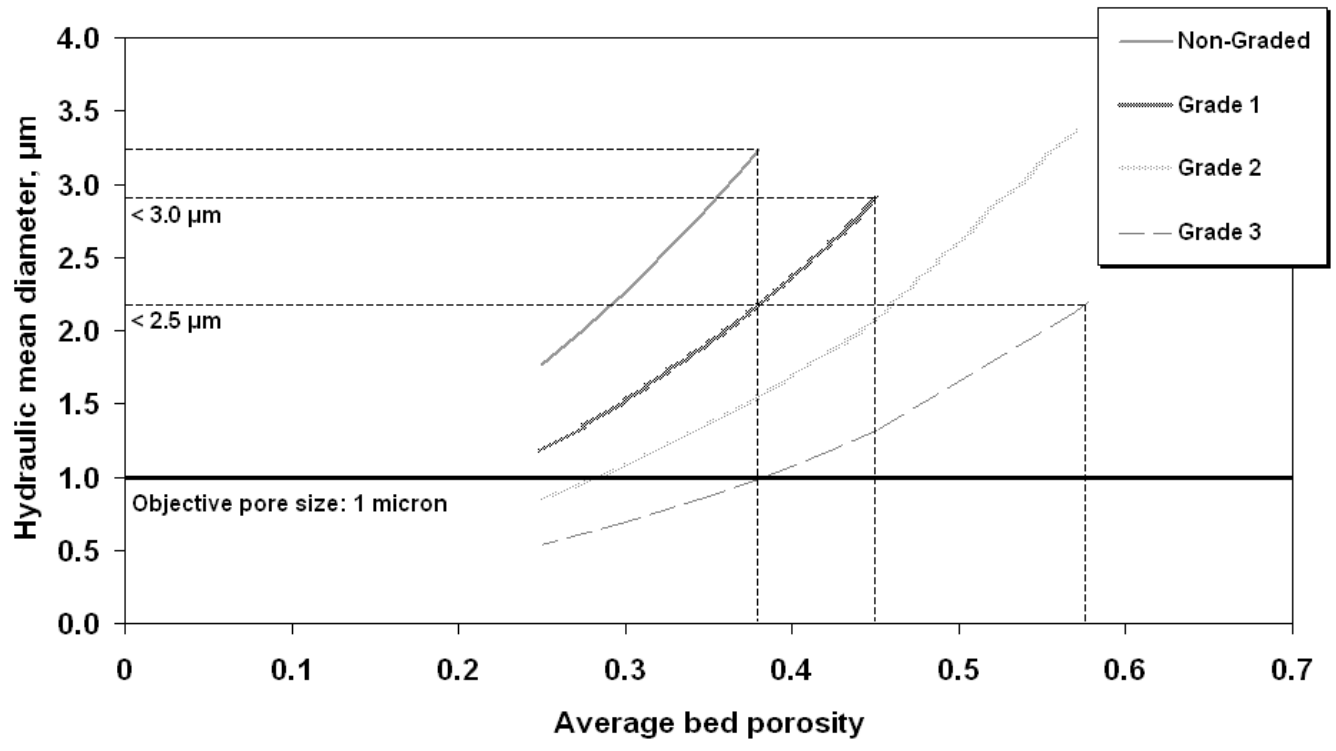

Figure 9 Predicted hydraulic mean diameters through a particulate bed for the available sizes of glass beads and different sintered bed porosities 


\section{LIST OF NOTATION}

c Suspension concentration $\left(\mathrm{kg} \mathrm{m}^{-3}\right)$

$d_{H} \quad$ Hydraulic mean diameter $(\mu \mathrm{m})$

$D_{i} \quad$ Particle diameter of the $i^{\text {th }}$ component $(\mu \mathrm{m})$

$\bar{D} \quad$ Average particle diameter $(\mu \mathrm{m})$

$\Delta P \quad$ Trans-membrane pressure $(\mathrm{Pa})$

$\Delta P_{o} \quad$ Initial pressure drop (Pa)

$-\quad$ Average bed porosity

$\varepsilon_{A} \quad$ Surface porosity

$f_{i} \quad$ Fractional quantity of the $i^{\text {th }}$ component

$\mathrm{J} \quad$ Permeate flux $\left(\mathrm{I} \mathrm{m}^{-2} \mathrm{hr}^{-1}\right)$

$\bar{n} \quad$ Number of hypothetical particles surrounding a central particle

$S_{V} \quad$ Specific surface $\left(\mathrm{m}^{-1}\right)$

$t \quad$ Filtration time (s)

$y \quad$ Blocking area $\left(\mathrm{m}^{2} \mathrm{~kg}^{-1}-\right.$ dry solids $)$ 